\title{
Surgical Correction of Single Atrium after Miscarriages
}

Kojqiqi $F^{1,2^{*}}$, Kojqiqi $A^{1,2}$, Jusufi $\mathrm{I}^{3}$ and Kojcici $\mathbf{B}^{1,2}$

${ }^{1}$ Department of Cardiac Surgery, American Hospital Kosovo, Rr. e Shkupi 25, 1000 Pristina, Kosovo

${ }^{2}$ Department of Cardiac Surgery, American Hospital 3, Albania, Rr. Sabaudin Gabrani, Tirana, Albania

${ }^{3}$ Department of Anesthesiology, American Hospital Kosovo, Rr. e Shkupi 25, 1000 Pristina, Kosovo

"Corresponding author: Kojqiqi F, MD, Department of Cardiac Surgery, American Hospital Kosovo, Rr. e Shkupi 25, 1000 Pristina, Kosovo, Tel: +38349878373; E-mail: fatos@kojqiqi.com

Received: November 28, 2018; Accepted: December 13, 2018; Published: December 20, 2018

Copyright: $\odot 2018$ Kojqiqi F, et al. This is an open-access article distributed under the terms of the creative commons attribution license, which permits unrestricted use, distribution, and reproduction in any medium, provided the original author and source are credited.

\begin{abstract}
We present a successful surgical repair of a single atrium (SA) in a 27 -year-old woman, who had a complete missing of the atrial septum, without any coexisting valvular pathology. The SA diameter was $9.97 \times 6.18 \mathrm{~cm}$ and the $\mathrm{Qp} / \mathrm{Qs}$ were 4.1 due to single atrium. Surgical correction consisted in creating a new atrial septum, using doublevelor patch. First and second year follow up, patient in very good condition and without any symptoms present. We consider that the diagnoses of single atrium, especially in child bearing women is done in appropriate time, in order to avoid miscarriages and other complications associated.
\end{abstract}

Keywords: Single atrium; Common atrium; Miscarriages

\section{Introduction}

Single atrium is a rare heart condition, in which inter atrial septum is missing, without atrioventricular valve pathology. These congenital heart defects are surgically corrected after birth. Patient we are going to present is a grown-up lady, who underwent successful surgical correction of the defect after three aborts.

\section{Case Report}

A 27-year-old female patient was referred to our hospital with rhythm disturbances, cianozes and weight loss. She has been seen previously by gynaecologist for other reasons and finally seen by cardiologist who noticed on echocardiography a single atrium. She went through three spontaneous abortions. During her life she avoided sport and other physical activities. She started working as a hairdresser in order to avoid exercise.

After her marriage, she had three abortions (her first pregnancy was terminated spontaneously on 29-week gestation, her baby was only 810 gm in weight and died few hours later. Her second pregnancy again was terminated spontaneously at 23 weeks. Baby weight was $360 \mathrm{gm}$ died couple of hours later. Her third and last pregnancy was ended at 30 weeks gestation, baby died couple of hours later), what made her to seek medical advice. After her third baby loss, her gynecologist noticed that she had supraventricular extra systoles and referred her to cardiologist, who on echocardiography noticed a single atrium and referred her to us for surgical treatment. She was not diagnosed with heterotaxy syndrome. In our clinic she presented with mild cyanoses of her fingers and lips. She told us that her feet and hands have been cold since childhood and on exercise she gets difficulty in breathing.

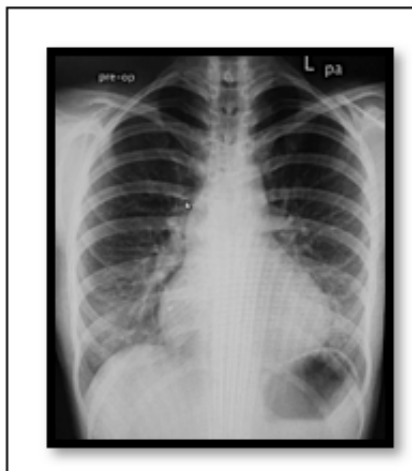

a)

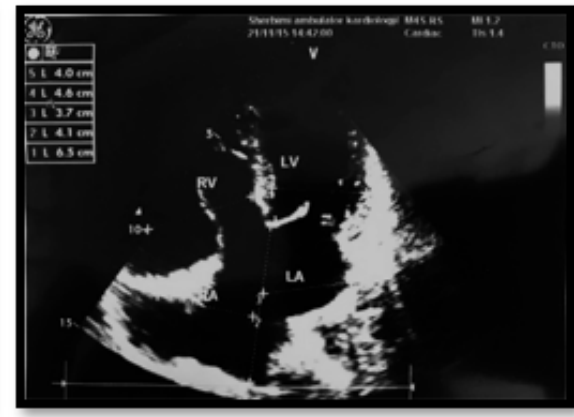

b)

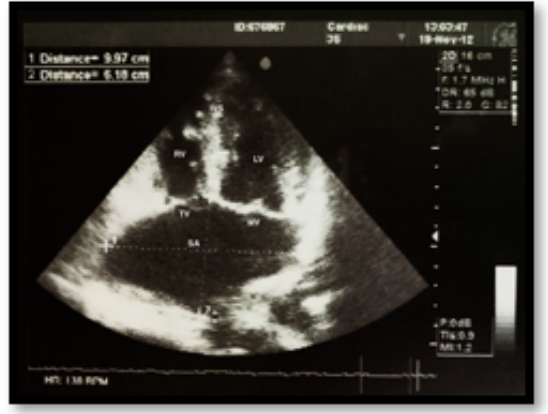

c)

Figure 1: Pre-operative diagnostic. a) Chest X-Ray, b) Echocardiography, c) Four chamber view. 
Chest radiography: Demonstrated cardiomegaly, right atrial and right ventricular enlargement and a prominent pulmonary trunk (Figure 1a).

Echocardiography, TTE: Noticed single atrium, diameter $9.97 \mathrm{~cm}$ with $6.18 \mathrm{~cm}$ LVEF 60\%. Mitral and Tricuspid valve insufficiency grade I-II, same level offset and PAP 40-45 mmHg. Dilated right ventricle (33 $\mathrm{mm}$ ), TAPSE $22 \mathrm{~mm}$ Qp/Qs 4.1 (Figures $1 \mathrm{~b}$ and 1c).

TEE: Left shift of the interventricular septum, aortic valve with three normal leaflets, mitral valve with myxomatous leaflets, mild insufficiency grade I-II. Mild tricuspid valve insufficiency.

CT angiography: Single atrium with normal drainage of pulmonary veins, superior and inferior vena cava. Saturations on room air $91 \%$, on arterial gasses $\mathrm{PO}_{2} 69 \mathrm{mmHg}, \mathrm{SaO}_{2} 89 \%$.

\section{Surgical Procedure}

Standard Sternotomy Aortic and bicaval canulation. After opening of the right atrium, we noticed complete absence of the interatrial septum (Figures $2 \mathrm{a}$ and $2 \mathrm{~b}$ ). Superior and inferior pulmonary veins from the right and left lung drained into what supposed to be left atrium. Mitral and Tricuspid valve with normal morphology. Coronary sinus opened normally into right atrium. After careful inspection of the entire atrium, we started to create an interatrial septum, with double pericardial patch. As described by Jing Wang (second Technique [1]) we started sutures (4-0 Prolen) from the middle of the ventricular septal crest downward to the borderline between the tricuspid septal valve annulus to the left inner side of the coronary sinus to the remaining border of the atrial septum. The Patch was sutured with running sutures and with extra fixating mattress suture without pledgets were taken every $2-3 \mathrm{~cm}$.

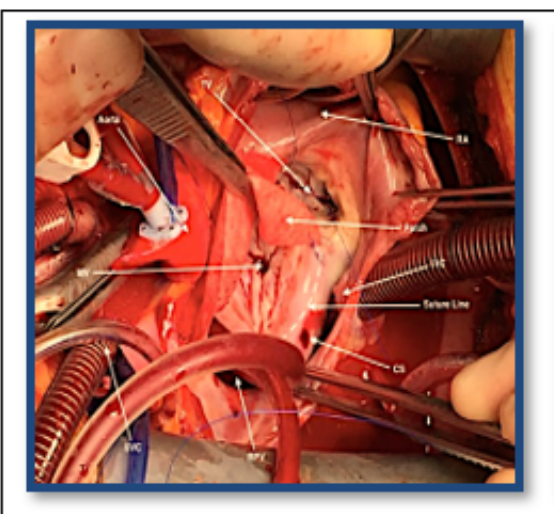

a)

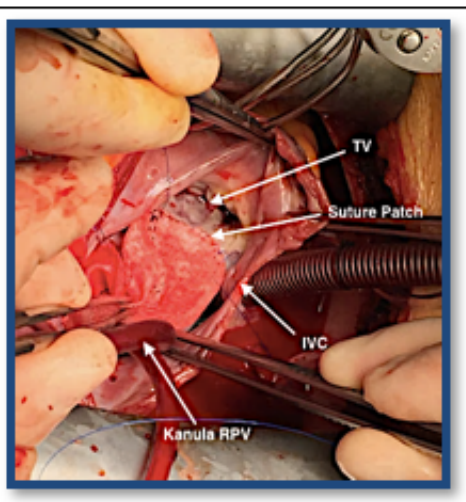

b)

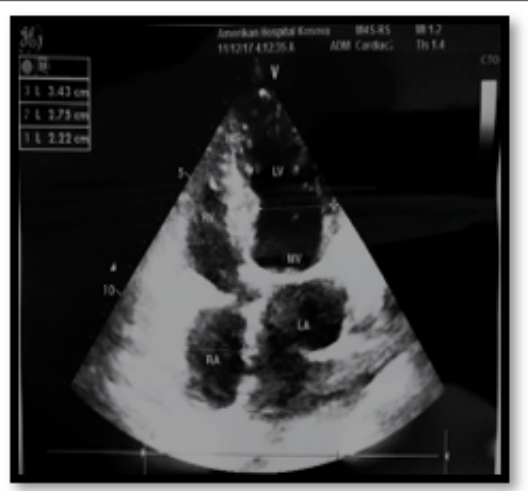

c)

Figure 2: (a) TV and MV with the patch in the middle and the suture line where the patch would suture at the posterior border of CS. (b) Right Atrium, view of tricuspid valve. (c) Echocardiography, follow up after 1 year. (Note: A- Aorta, TV: Tricuspid Valve, IVC: Inferior Vena cava, SVC: Superior Vena cava, CS: Coronary sinus, RPV: Right Pulmonary Vein).

Intra-operative TEE showed that there was a mild degree of mitral and tricuspid valve insufficiency (Grade I). There was no inter-atrial defect remained. Right atrium with normal size however mildly enlarged left atrium. Postoperative we don't have atrial fibrillation and AV block, however saturations dropped to $84-85 \%$. Mitral Valve has a minimal insufficiency Grad I-II with v.contracta $0.2 \mathrm{~cm}$ on echocardiography (Figure 2c). The PSAP post-operative is $29 \mathrm{mmHG}$ and the RVSP is $23 \mathrm{mmHg}$. Anticoagulation with Cumarine (International Normalized Ratio- INR 2.5-3 was given for a period of six months). Mitral valve has a minimal insufficiency on echocardiography (Figure 2c). Follow up after first and second year, patient was in very good condition and with a good result.

\section{Discussion}

There are few case reports involving common atrium also known as single atrium [1]. Rastelli and associates [2] reported few cases were the absence of the atrial septum was accompanied by presence of the cleft into the anterior leaflet of the mitral valve and the absence of inter-ventricular communication. On the other hand, Levy and associates [3] reported a case were the complete absence of the atrial septum was not accompanied by other defects as described by Rastelli, suggesting that this condition can be exist alone as a specific entity.
Our case supports Levy and associate's recommendation; therefore, a term single atrium will be used in this report.

The clinical picture of our patient, cyanoses, rhythm disturbances, weight loss and reduced exercise tolerance started years back. This clinical presentation does not differ from patients diagnosed with a large atrial defect at the fossa ovalis [3]. In single atrium the blood (arterial and venous) is mixed, which explains mild cyanosis, shortness of breath, increased fatigability [4] and reduced exercise tolerance early in life [5].

Surgical correction should be done early in life to prevent later complications. Our patient unfortunately was diagnosed very late and only after going through three abortions. Surgical repair consists in creating two atria, using a patch, which could be a Dacron or an autologous pericardial patch. For reconstruction of the Atrium we used artificial patch as we could not obtain a fixating solution for native pericardium. The suture method was as described by Jing Wang (second Technique) [1] and we leave the Coronary sinus to the right Atrium. We can report that the reconstruction was very successful without any injury of AV Bundle and residual Shunt.

In the initial recovery period, we noticed a reduction in $\mathrm{SaO}_{2}$, from $93 \%$ preoperatively to $84-85 \%$ during the first 30 Days post-op. The 
Citation: Kojqiqi F, Kojqiqi A, Jusufi I, Kojcici B (2018) Surgical Correction of Single Atrium after Miscarriages. J Cardiovasc Dis Diagn 7: 351.

$\mathrm{SaO}_{2}$ values stabilized within one year from surgery. At present her $\mathrm{SaO}_{2}$ values are maintained at $97 \%$, with $\mathrm{pO}_{2} 66 \mathrm{mmHg}, \mathrm{pCO}_{2} 28.4$ $\mathrm{mmHg}$. She keeps very active and for the first time she does not complain of tiredness or cyanosis is present.

Congenital Heart Disease Guidelines from 2010, recommend that a team of Cardiologist, Gynecologist and Anaesthetist should discuss and follow before pregnancy patients who can be complicated during pregnancy and offer adequate treatment. Our patient makes us to support strongly these recommendations. Our patient was presented with a heart defect, which was undiagnosed for years and costs our patient three miscarriages and lately divorce. This history makes us push forward the need for guidelines to be followed and implement in every institution which treat pregnant women. Patients like ours not only will bear the consequences of losing three pregnancies but losing her family as well which will have psychological implications too.

\section{Conclusion}

Surgical correction of a single atrium can be done with good results and without any later complications. The long-term survival is very good.

\section{Conflicts of Interest}

There are no conflicts of interest for the present study.

\section{References}

1. Jiang H, Wang H, Wang Z, Zhu H, Zhang S, et al. (2013) Surgical correction of common atrium without non-cardiac congenital anomalies. J Card Surg 28: 580-586.

2. Rastelli GC, Rahimtoola SH, Ongley PA, McGoon DC (1968) Common atrium: Anatomy, hemodynamics and surgery. J Thorac Cardiovasc Surg 55: 834-841.

3. Levy MJ, Salomon J, Vidne BA (1974) Correction of single and common atrium, with reference to simplified terminology. Chest 66: 444-446.

4. Hirai S, Hamanaka Y, Mitsui N, Isaka M, Mizukami T (2003) Surgical repair of a common atrium in an adult. Ann Thorac Cardiovasc Surg 9: 130-133.

5. Asano KI, Sakurai Y, Matsuzawa H (1969) Surgical correction of common atrium with anomalously connected persistent left superior vena cava. Jap Heart J 10: 545-551. 